\title{
Asimilaciones Teóricas De Severo Sarduy. Comentarios Sobre la ANalogía Plástica
}

Silvana F. Santucci

UNL-UNC-Conicet silvanasantucci@gmail.com

Resumen: En el marco de lo que Raúl Antelo (2008, 2009, 2011) ha practicado y definido como "un trabajo archifilológico con textos latinoamericanos", proponemos una primera aproximación al concepto de analogía plástica delineado por Severo Sarduy en sus ensayos. Creemos que este concepto constituye una puerta de entrada teórica apropiada para la comprensión de las filiaciones y vínculos entre literatura y plástica presentes en la obra del autor cubano. En consecuencia, mostramos un recorrido que toma en cuenta la bibliografía teórica sobre el campo de relaciones interartísticas desde una perspectiva histórica no coincidente, necesariamente, con una diacronía. Este modo de revisar la historia y el arte es consecuencia de la propia inscripción teórica que Severo Sarduy hace del tiempo. Por lo tanto, revisamos el concepto sarduyano de "analogía plástica" como una inscripción teórica legible sobre estas relaciones, pensada en clave del parérgon griego: un registro incidental, colateral, un apéndice.

Palabras- Claves: Severo Sarduy; analogía plástica; trabajo archifilológico.

Abstract: Within the framework of what Raúl Antelo $(2008,2009,2011)$ has practised and defined as "an archiphilological work with Latin American texts", this article proposes a first approach to the concept of "plastic analogy" outlined by Severo Sarduy in his essays. We believe that this concept constitutes an appropriate theoretical gateway to understand the filiations and connections between literature and plastic art present in the said work. Consequently, we show a study that considers the theoretical bibliography on the field of interartistic relations from a non-coincident historical perspective, necessarily, with a diachrony. This way of revising history and art is a result of the theoretical inscription Severo Sarduy makes about time. Therefore, we revised the Sarduyan concept of "plastic analogy" as a theoretical, legible inscription about these relations, conceived from the Greek parergon: an incidental, collateral register, an appendix. 
Keywords: Severo Sarduy; plastic analogy, archiphilological work.

\section{Introducción}

La obra de Severo Sarduy ha dado lugar a una multiplicidad de lecturas críticas que exceden lo enumerable en unas pocas páginas. Sin embargo, la relación que esta obra traza con la plástica emerge como un tópico que comienza a ser explorado, de modo sistemático, por las agendas de lecturas críticas especializadas, en los últimos años (León, 2001; Laddaga, 2007; Pérez, 2012). En este artículo, nos proponemos revisar un concepto central para el conjunto de estudios que se ocupan de estos cruces interartísticos: la noción sarduyana de "analogía plástica". La misma, hasta el momento, no ha sido sólidamente valorada en sus implicancias teóricas y en sus alcances conceptuales en tanto metáfora disolutiva de la relación entre las artes. Éstas últimas, organizan sus desarrollos teóricos sobre la vertiente histórica y comparativa, iniciada con la tradición horaciana del ut pictura poesis. Sin embargo, en la propuesta de Severo Sarduy, pintura y literatura se conjugan como "el mismo perro con distinto collar"1. De este modo, se disuelven y discuten los marcos tradicionales de abordaje de las relaciones entre las artes, entendidos como sistemas de signos disímiles.

En correspondencia con lo antedicho, el concepto sarduyano de "analogía plástica" se aleja de los esquematismos y traslada sus interrogantes al territorio de las investigaciones contemporáneas que vinculan las nociones de "imagen" y "escritura", requiriendo, por lo tanto, un análisis que las aborde en la complejidad de su dimensión conceptual. Al respecto, el enfoque teórico-crítico propuesto por Raúl Antelo, denominado “archifilología”, presenta un método de abordaje de los textos literarios que resulta una alternativa eficiente para el análisis de estas relaciones, en la medida en que permite comprender los bordes permeables y las relaciones de extimidad que las recubren.

En consecuencia, presentamos un escrito organizado en dos partes. La primera, recorre las implicancias conceptuales que supone el trabajo con el espectro teórico-critico de la "archifilología” y la segunda, retoma las consideraciones específicas de Severo Sarduy en torno a la "analogía plástica", el término que nos ocupa.

\footnotetext{
1 Sarduy. Obras Completas p. 78
} 


\section{Sobre el trabajo archifilológico.}

Raúl Antelo, en un curso dictado en la Universidad Nacional de Córdoba, en agosto del año $2012^{2}$ presentó algunas previsiones en torno a la construcción de una lectura archifilológica de textos latinoamericanos. En el mismo, propuso un método poético como dispositivo de lectura de la literatura y el arte, centrado en la búsqueda de relaciones posibles (una estética operante) al interior y al exterior de los objetos artísticos, dispuestos en una relación de extimidad. ${ }^{3}$ La perspectiva teórico-estética presentada basó sus presupuestos formales en la reconstrucción del archivo y en la mostración del dato, como programa. ${ }^{4}$ Por otra parte, el plural con que esta práctica crítica aparece recubierta, ilustra el borramiento de toda búsqueda de un sentido fundacional en los objetos, a la vez que "rechaza las imágenes plenas y los señuelos de la representación". Esta clave de lectura, centrada en textos contemporáneos, asume a la modernidad como "un guión, un roteiro o derrotero, un movimiento en dirección al movimiento pero también una secuencia de discontinuidades". Por lo tanto, cualquier trabajo que quiera pensarse en el marco de una archifilología debería participar, siguiendo a Antelo, de un pensamiento posfundacionalista: es decir, perseguir una imagen que, según apuntaba Raúl Antelo en el citado curso, no es original, ni copia; ni arcaica, ni contemporánea, pues mediante ella, se buscará evidenciar un nuevo montaje de la historia que no sea efecto residual del tejido de múltiples pasados, sino una suspensión anacrónica en la

\footnotetext{
${ }^{2}$ Hacemos referencia al Curso de Posgrado: "Archifilologías latinoamericanas. La modernidad como escena del crimen”, dictado por el Dr. Raúl Antelo (UFSC-CNPq) en la Universidad Nacional de Córdoba, Argentina, en Agosto de 2012. Sin embargo, el crítico ensayó buena parte de los protocolos de escritura teóricos que allí se presentan, en diversas publicaciones anteriores $(2008,2009,2011)$.

${ }^{3}$ Esta palabra que Jacques Lacan inventó en su seminario sobre La ética del psicoanálisis (1958) y que Jacques-Alain Miller rescató y reutilizó en 1985, puede definirse como "goce que toma las formas más variadas de síntoma": "algo exterior, confiado a sí mismo, rechazado del lenguaje. Ya no es éxtimo al Otro sino forcluido y retorna en lo real"(Miller, 2010, p.20). Antelo, por su parte, en Crítica Acéfala la define como: "un lugar simultáneamente interno-externo, metido en la cueva de lo propio pero abierto asimismo a la indefensión de la vida. En ese sitioguión, ni plenamente mimético, ni totalmente mágico, sino ético, se esboza un más allá del sujeto y un más allá de lo moderno" (Antelo, 2008, p.28). Sarduy, por su parte, va a poner a circular este concepto cuando propone al sujeto moderno como un "exilado de sí mismo"(1990)

${ }^{4}$ Daniel Link ante la presentación de Crítica Acéfala, denomina "con temerosidad" a este tipo de trabajo: "un esfuerzo de crítica genética", p.220.

${ }^{5}$ Link. "Crítica Acéfala", p. 222

${ }^{6}$ Antelo. Crítica Acéfala, p. 13
} 
que se pongan de manifiesto, modos de relación entre el fenómeno y el archivo. Un vínculo, en cuya pervivencia se encontraría una estructura analógica bipolar.

Desde este ángulo, la deconstrucción de la autonomía del arte planteada por Josefina Ludmer en las ya célebres "Literaturas Posautónomas" (2007) puede servir como ejemplo para ilustrar el registro de conexiones bipolares presentes en el posfundacionalismo. En sus "Notas para Literaturas Posautónomas III" Ludmer observa que -como advierte Beatriz Jaguaribe en O choque do real. Estética, mídia e cultura (2007)- el desarrollo de las tecnologías de la imagen y de los medios de reproducción ha liberado "una forma de imaginario donde la ficción se confunde con la realidad", emergiendo como una realidadficción. Sin embargo, este cruce no sería ya "una materia hecha de las dos, no es una mezcla, un mestizaje, un híbrido o una combinación, sino una fusión donde cada término es, de un modo inmediato, el otro: la realidad ficción y la ficción realidad". P Por lo tanto, extrapolable como "analogía bipolar" este concepto instala los términos de cruce como fusiones, como alternativas a las disyuntivas, tal como puede observarse en el ejemplo anterior.

Sin embargo, en otro caso, podrían tomarse como ejemplo de esta bipolaridad las intervenciones en relación con la dualidad naturaleza/cultura producidas tanto por Georges Bataille9 (1933), como por Roger Caillois (1937) o por el propio Severo Sarduy en La simulación (1982). Severo Sarduy, por ejemplo, manifiesta tener "al igual que Lezama”, una enorme deuda

\footnotetext{
${ }^{7}$ Antelo. Crítica Acéfala, p. 13

${ }^{8}$ Ludmer. "Notas para Literaturas Posautónomas III", p. 1-3

9 En "La noción de gasto" (1933), George Bataille se ocupa de pensar la economía sin renta por objetos de valor cuando estudia la figura del potlatch como principio económico. El potlatch, por definición, se configura como un tipo arcaico de intercambio anterior al trueque que practicaban ciertas tribus aborígenes del norte de Estados Unidos como los Haida, los Tlingit, Tsimshian, los Salish, y los Kwakiutl. Alejado de la noción de "gasto productivo" el potlatch era una institución ritual, o celebración de la pérdida que consistía en la entrega de un don o bien en la destrucción de una suma considerable de riquezas por parte de un donador, para desafiar a un rival (donatario). Bataille indica que en estas civilizaciones antiguas el potlatch era llevado a cabo en iniciaciones, matrimonios y funerales y no podía ser disociado de una fiesta, "bien porque el potlatch ocasione la fiesta, bien porque tenga lugar con ocasión de ella" (La noción de gasto, p.5). El potlatch siempre estaba ligado a una demostración de poder, así, riqueza y poder eran entendidos como "poder de perder", aspecto que sostenía a la economía mediante un principio de pérdida. Todo potlatch debía ser devuelto con usura, es decir, respondido y superado en un plazo determinado por el rival a partir de la entrega de un don (o potlatch) más importante. De esta manera, la capacidad de pérdida estaba unida no sólo a la riqueza como cantidad sino a la gloria y el honor. Como indica Bataille, el potlatch "es la constitución de una propiedad positiva de la pérdida", de la cual emanan la nobleza, el honor y el rango en la jerarquía, dando a esta institución su "valor significativo". El don, dice, "debe ser considerado como una pérdida y también como una destrucción parcial, siendo el deseo de destruir transferido, en parte, al donatario" (Bataille, La noción de gasto, p.6). Por lo tanto, esta lógica de intercambio, mediante el don, vuelve ambivalente todo valor. De acuerdo con Martin Jay cabe considerar que la "experiencia" para Bataille: "era precisamente todo cuanto trascendía los intentos del discurso de validar sus afirmaciones" (Jay, 2009: 433). Aspecto también visible en los protocolos de escritura sarduyanos.
} 
con El mito y el Hombre (1937) de Roger Caillois. Según declara, le comentó en persona "pues eran muy amigos" que:

Se comprobó con estadísticas norteamericanas (...) que los pájaros de una región dada devoran tanto mariposas pigmentadas, es decir, con ocelos como mecanismo de defensa e intimidación, como mariposas en que esto no ocurre. Ergo, ese camuflaje defensivo, ese enorme gasto de volutas, de iridiscencias, de ocelos, de vetas, es totalmente inútil, donde yo concluyo, abusivamente, que el barroco ya se encuentra en la naturaleza. ${ }^{10}$

Por lo tanto, en estos trabajos la noción de "mimetismo" cobra valor como aspecto disolutivo que va inscribiendo toda una genealogía en el campo de los estudios literarios latinoamericanos que vale la pena revisar y reconstruir.

Por otra parte, si hablamos de una "estética posfundacionalista" cabe tomar en cuenta el modo en que Susan Buck-Morss relee los presupuestos Benjaminianos asumiendo a la estética "como discurso del cuerpo" derivado de la experiencia de los sentidos y perteneciente, por tanto, al campo de la naturaleza corpórea, material, estésica ${ }^{11}$ y no como lo propone el pensamiento autotélico o autogénetico, que lo vincula a formas culturales producidas estrictamente bajo el control del hombre, términos diseñados, en su definición, bajo la forma de "arte" o de "política". ${ }^{2}$

Es, por esta vía, que la faz dialéctica bipolar propuesta por Antelo -la que podría, también, ser pensada bajo la relación entre estésica y anestésica, en correspondencia con los planteos teóricos que retoma Leonel Cherri ${ }^{13}$ - puede incluirse en el marco de las fusiones que Lacan ha definido bajo la fórmula del “...o peor", en correspondencia con las lecturas de Severo Sarduy. Casualmente, esta fórmula se dispone en el seminario XIX, en cuyo interior Lacan funde las nociones de niño y niña, remarcando la afamada inexistencia de la relación sexual. Este “... o peor”, que elidiría al verbo (según Lacan este tipo de adverbios se usa, por ejemplo, para decir: "hago bien, hago peor") subraya la importancia de ese lugar vacío y demuestra con ello: "el señalamiento de que el vacío es el único modo de atrapar algo con el

\footnotetext{
${ }^{10}$ Sarduy. "Entrevista" por Jorge Schwartz, p.1832

${ }^{11}$ Cherri. "Políticas de muerte y políticas de sentimiento en un corpus latinoamericano", s.p.

12 Buck-Morss. Benjamin Escritor Revolucionario, p.173-175. En dicho volumen se ejemplifica al bomo autotelus, desde lo que se asume como "el nacimiento de la polis griega". El mismo es atribuido "a la asombrosa idea de que el hombre puede producirse a sí mismo ex nibilo. La polis deviene artefacto del "hombre", en el cual éste puede dar a luz, como realidad material, su propia esencia superior. De manera similar, Maquiavelo elogió al Príncipe que por sus propios medios funda un nuevo principado y conectó este acto autogenético con el apogeo de la virilidad.”

${ }^{13}$ Buck-Morss. Benjamin Escritor Revolucionario, p. 167-221
} 
lenguaje". ${ }^{14}$ Noción similar al prorrogativo "I would prefer not to" de Bartleby, que manifiesta un deseo negativo del sujeto, mediante el cual sólo obtiene tiempo. Desde este ángulo, entonces, el vacío marcado por Lacan aparece dispuesto en relación con la propia esencia del significante (el órgano benjaminiano o "la mariposa muerta" para Didi-Huberman ${ }^{15}$ ), pues la instancia temporal es configurada como una mediadora en la planificación de casi cualquier lectura que se proponga acercarse al archivo. De esta manera, como propone Antelo, la archifilología nos impondría siempre una condición in-condicional: la contingencia, lo aleatorio y lo fortuito. Término que Sarduy recupera bajo la noción del "súbito lezamiano":

Atribuyendo a esta palabra [el súbito], como hiciera el propio Lezama, un sentido más vasto que el que tuvo en su definición original (una coincidencia fonética reveladora) y dándole el de una sorpresa del relámpago conceptual, que une, como en un campo magnético, lo más disímil, lo antípoda: el agua de coco y la lechuza, las ventanas y el albortón. ${ }^{16}$

Marco este contrapunto antagónico y aglutinante propio de la alquimia insular, en la medida en que Severo insiste a continuación en producir una lectura dispuesta "en clave de estos conjuros" $" 17$, resultando partidario por excelencia del estudio de las causalidades acrónicas: "No tengo sentido alguno del tiempo, [afirma] no comprendo la sucesión de eventos ni me parece que correspondan a instantes precisos, no creo en la idea de continuidad"18. Por lo tanto, desde la noción operativa de retombeé que, en 1974, define como "isomorfía no contigua" $" 19$ o desde la recuperación del concepto eón, (idea-acontecimiento) propuesta por Eugenio d'Ors en "Lo barroco" (1935) e incluso, retomando su interés por el concepto de "biografema" barthesiano, ${ }^{20}$ Sarduy se nos aparece, hoy, como un teórico del mimetismo, que precisa los ejes de su trabajo a la sombra de lo que definió como "arte hipertélico"21.

${ }^{14}$ Lacan. ... O peor, p.11-12

${ }^{15}$ Didi-Huberman. Ante el tiempo, p.31

${ }^{16}$ Sarduy. Obras completas, p.1415

${ }^{17}$ Sarduy. Obras completas, p.1415

${ }^{18}$ Sarduy. Obras completas, p. 6

${ }^{19}$ Dice Sarduy: "Llamé retombeé a falta de un mejor término en castellano, a toda causalidad acrónica. La causa y la consecuencia de un fenómeno dado pueden no sucederse en el tiempo, sino coexistir; la «consecuencia» incluso, puede preceder a la «causa»; ambas puede barajarse como en un juego de naipes. Retombeé es también una similaridad o un parecido en lo discontinuo: dos objetos distantes y sin comunicación o interferencia pueden revelarse análogos; uno puede funcionar como el doble -la palabra también tomada en el sentido teatral del término- del otro: no hay ninguna jerarquía de valores entre el modelo y la copia". "Nueva Inestabilidad", Obras completas, p.1370

20 La noción de "biografema" alejada de la historización de eventos de la vida de un sujeto normalmente considerados en una "biografía", se ocupa de los fragmentos que se anuncian como efectos de lenguaje, "más allá" del referente tras el nombre propio que lo custodia y el cuerpo que lo gesta. El surgimiento del biografema acompaña un cambio en la mirada sobre las vidas biografiadas, implicando un nuevo tratamiento. Se trata de otra 
Por su parte, Severo retoma la potencia estésica de la naturaleza para equipararla con los poderes de la literatura y de los fenómenos plásticos. El soporte que da unión a dicho vínculo se cifra en la voluntad (o el "deseo", como va a preferir), presente en ambos dominios, de ir más allá de sus fines, de exceder las predisposiciones, los ánimos o las inclinaciones que pudiera haber conjugadas desde el discurso del cuerpo, y por lo tanto, desde la estésica como predestinación. Las implicancias que se derivan de este tipo de consideración sobre la literatura suponen que el carácter de "inutilidad", de "gasto" y de "exceso" que recubre a los objetos de arte barrocos comparte, más allá de la representación mimética, un mismo proceso con las entidades naturales: aquellas que, como Severo ejemplifica, se tramitan bajo un impulso de muerte. ${ }^{22}$ En consecuencia, en términos sarduyanos, el tiempo es asumido como un extraño espejo o corriente, que hace circular, tanto las "imágenes inmóviles del pasado", como las "reverberaciones de la memoria", expandiendo, reiteradamente, en la revisión del pasado la posibilidad de un por venir. ${ }^{23}$

La lectura, desde esta perspectiva, es plausible y eficiente, en parte, cuando se configura como un movimiento del presente, donde los "herederos" conciertan aleatoria y acrónicamente, bajos los parámetros del lenguaje, un mundo hecho de desconciertos y malos entendidos: "Lezama practica con los textos que lee lo que más tarde Lacan propondrá frente al discurso de los analizantes: una escucha distraída, la única que revela, no la trama aparente,

postura de lectura, de selección y valoración de los signos de vida, puesto que llama a focalizar el detalle y la potencia de aquello que en apariencia puede ser ínfimo, pero que ingresa al proceso creador del sujeto, en tanto productor de escritura y de vida. Cfr. Barthes.Sade, Fourier, Loyola, p. 12

${ }^{21}$ En "Pintado sobre un cuerpo", uno de los ensayos recogidos en La Simulación (1982), Sarduy desarrolla la noción de arte bipertélico. Al respecto, apunta: "Llegada la marea del equinoccio, ciertos animales ciliados retroceden excesivamente sobre la arena, huyen demasiado lejos hacia el interior de la tierra. Cuando el mar se calma, son incapaces de volver a alcanzarlo: mueren en el exilio, tratando en vano de regresar al agua, cada vez más lejana, de recorrer al revés el camino que un impulso irresistible, inscrito en ellos desde su nacimiento y saturándolos con su energía, les había obligado a tomar", Obras Completas, p. 1293. A partir de este ejemplo, define la hipertelicidad como: "la posibilidad del arte y de la naturaleza de ir más allá de sus fines", Obras Completas, p.1298. Y describe lo que entiende como una «voluntad» de los ciliados por manifestar un «fasto», una «inutilidad» y un «exceso» que los conduce a la muerte En su propuesta, la naturaleza sólo puede superar sus fines mediante una voluntad cifrada en su saber genético. En la medida en que trasvasa la conservación, instala un vacío entre los límites de vida y de muerte que funda, como el barroco, una identidad "no idéntica al objeto", Obras Completas, p.1294. En correspondencia con este ejemplo, Sarduy posiciona al neobarroco, como un saber que quiere instalarse "más allá de sí mismo", es decir, fundar un lenguaje alejado de los intercambios eficaces y de los modos de regulación de las "buenas y malas" maneras de hacer arte. Un desarrollo completo de los alcances de esta noción ha sido presentado en otro artículo: cfr.: Santucci, Silvana. "Sarduy y el neobarroco. Interpretaciones sobre lo político en el arte",

${ }^{22}$ En La Simulación (1982) retoma el ejemplo de orugas, mariposas y otros animales ciliados.

${ }^{23}$ Sarduy. Obras completas, p.1415 
sino el tejido secreto, la armazón invisible de la escritura". ${ }^{24}$ De esta manera, desde el espacio que los signos y sus valores culturales trazan como ambivalencias irreductibles (como indecidibilidades) que se muestran, a la vez, como identidades (positivas) y como diferencias. O lo que es lo mismo, como integrantes de una archiescritura, ${ }^{25}$ Severo multiplica los desvíos, los re-envíos y hasta los sin sentidos en la antinomia insoluble del tiempo. Aspecto que, siguiendo a Kracauer (1966) cabría reconsiderar:

Cuanto mayor se vuelve uno, más está obligado a reconocer que su futuro es el futuro del pasado: historia. (....) una vez que una visión se institucionaliza, nubes de polvo se acumulan a su alrededor y vuelven borrosos sus contornos y contenidos. (...) Quizá su período inicial sea el más transparente a las verdades a las que apunta en medio de dudas ${ }^{26}$

Por lo tanto, nuestra revisión de la escritura sarduyana, atiende a sus propias prerrogativas. Severo asumía que una buena lectura debía buscar la "consecuencia de algo que aún no se ha producido" y su parecido con "algo que aún no existe". ${ }^{27}$ Creemos que es, en clave de esta matriz, que Antelo insta a leer archifilológicamente los textos, tratando de devolverles su fuerza de por venir.

\section{La analogía plástica}

Según sus propias declaraciones Severo Sarduy inicia su actividad como pintor, junto a Roland Barthes, a partir de la década de 1980, ${ }^{28}$ al tiempo que comienza a exponer algunos de sus cuadros en diversas muestras colectivas. ${ }^{29}$ Sin embargo, en sus escritos, la noción de “comparación plástica" es usada como procedimiento crítico a partir de 1985, en "Soy una Juana de Arco electrónica, actual”. Pero no es hasta 1989 que dicho concepto se consolida

${ }^{24}$ Sarduy. Obras Completas, p. 1414

${ }^{25}$ Derrida. La différance, p.12

${ }^{26}$ Kracauer. Historia. Las últimas cosas antes de las últimas.p.194

${ }^{27}$ Sarduy. Obras Completas. p. 1196

${ }^{28}$ Sarduy. Obras Completas, p. 1835. Allí dice: "Juntos empezamos a pintar y luego de su muerte, descubrí en el catálogo de sus obras que, sin decírmelo, me había dedicado muchos de sus dibujos; otros me los dio y los conservo. Le traje de la india unos polvos de colores con los que pintó; me regaló esos trabajos".

${ }^{29}$ Se registran participaciones de Sarduy en las siguientes exposiciones Grupales: En el Museo Carrillo Gil, México, 1980. En el N.R.A, París en 1981. En el Espace Culturel Graslan en 1982. En el Museo de Arte Moderno de la Villa de París 1982. En la Bibliothèque Royale, Bruselas en 1982. En el Centre Culturel Editard, Ginebra en 1983. En el Centre d'Art Comtemporain, Bruselas en 1985. En la Galerie Ouverte, París en 1987. En el Palais de Arts, Toulouse, Francia, en 1986. En el Centre de Georges Pompidou, París en 1991. Por otra parte, hasta el momento se han llevado a cabo cinco exposiciones de su obra con carácter póstumo: En la Maison de l'Amerique Latine en 1994. En el Museo Nacional Centro de Arte Reina Sofía, 1998. En el CAAM de Las Palmas de Gran Canarias, 1998. En el Centro Cultural Español, Miami, Florida. 1998. En la Galería Lina Davidov, París, 1999. 
como analogía plástica, manifestando la bipolaridad que lo recubre, ya que lo propone en torno a una reflexión sobre su propio proceso de escritura. Específicamente, el término aparece en un ensayo mínimo sobre Las virtudes del pájaro solitario (1988) de Juan Goytisolo. Allí Severo enuncia: "no puedo pensar más que en función de imagen, de pintura, de color". La importancia de este concepto radica en que se ve obligado a "visualizar" el texto en ausencia, a trabajar con el recuerdo y con la reverberación que le provoca, puesto que al momento de sentarse a escribir una crítica sobre el mismo, advierte que ha dejado olvidado el libro en el barco en que viajaba. Por lo tanto, la asimilación sarduyana entre imagen pictórica y literaria parte del registro que asume a las distintas artes presididas por un mismo principio. Sin embargo, dicho principio poco tiene de sofisticación. De comienzo, no permite comprenderlas como dos ejes de una misma comparación, en la medida en que teóricamente asimila literatura y pintura como "lo mismo". Son "el mismo perro con distinto collar. Claro está con resultados diferentes. Aunque no tanto (...) son como las dos vertientes de un mismo techo, las dos caras de una misma moneda" que están fundidas en el marco de "un mismo fondo". 30

No obstante, así enunciado, el planteo no propone nada novedoso. Tal como apunta Ana Lía Gabrieloni, ${ }^{31}$ las comparaciones entre literatura y plástica y, específicamente, entre literatura y pintura, trazan con su historia una tradición que se remonta a los griegos. A partir del comentario que Plutarco atribuye a Simónides de Ceos en el siglo V a.c: "la pintura es poesía muda/silenciosa" y la poesía es "pintura que habla" el rasgo comparativo entre ambas artes queda sellado. Estas ideas proponen a la voz (y por lo tanto, al cuerpo marcado por la phonè) como un componente central en dicho vínculo. A su vez, la voz otorgaría distintos "grados de densidad" a las variables de la comparación. Por lo tanto, "encontraríamos en la poesía la ausencia de una presencia que habla y en la pintura la presencia de una ausencia muda" ${ }^{32}$ Siguiendo a Gabrieloni, asumidas en estos términos, literatura y pintura no sólo estarían unidas por sus carencias respectivas, sino que encontrarían unidad en los aspectos que comparten: "la misma fuente de ejecución y un mismo destino: la mano del artista y la necesidad de fijarse a un soporte material". ${ }^{33}$ Sin embargo, en este punto, Sarduy se distancia de las comparaciones tajantes que conservan espacios más o menos delimitados de géneros y sentidos, al punto que coincide con Derrida (1978) al tratar a las imágenes como parergonales.

\footnotetext{
30 Sarduy. Obras Completas p. 78

31 Gabrieloni. "Literatura y artes", p. 125

32 Gabrieloni. "Literatura y artes", p. 125

33 Gabrieloni. "Literatura y artes", p. 125
} 
Es decir, como participantes incidentales de los bordes permeables de la escritura, que atraen la atención sobre lo que usualmente es exterior a la misma, estableciendo pasajes, conexiones, entre un adentro de la escritura y un afuera, entre un componente esencial y otro inesencial, asumidos en el marco de una contaminación.

En la perspectiva histórica propuesta por Gabrieloni, la expresión del Ars Poetica horaciana, ut pictura poesis ("la pintura es como la poesía") concretó el sintagma comparativo que unificó los términos, pero, al mismo tiempo, diseñó una relación jerárquica que dio peso y relevancia a la poesía: la pintura debía ser como esta última. ${ }^{34}$ No obstante, fue Gotthold Lessing en el siglo XVIII quien limitó la travesía de la integración entre las artes, marcando una separación témporo-espacial: en la pintura los cuerpos se despliegan en el espacio y en literatura las acciones se articulan en el tiempo. ${ }^{35}$ Sarduy, por su parte, se muestra distante de estas perspectivas pero consciente de que asumiendo algunos parámetros de la comparación puede relegar a la pintura a un rol subsidiario. En consecuencia, asume la relación entre plástica y literatura en torno a los conceptos de "imagen" y "escritura", potenciando, de este modo, la reflexión sobre la noción teórica que más le interesa y que vuelve central en su trabajo: el mimetismo. Para Severo, el mimetismo es lo que mantiene unido el parergon de imagen y escritura:

Roland Barthes decía citando a Hobbes, "la pasión de mi vida ha sido el miedo", la de la mía, ya bastante avanzada, ha sido sin duda esa percepción del ser humano como algo falseado, como si la impostura fuera la esencia que lo anima y su motivación última la simulación. Un pesimismo fundamental no con respecto a las acciones del hombre, a sus proezas espectaculares, sino con respecto a su naturaleza misma y a su pulsión incontrolable para manipular a los otros, por simular, por mentir. Un ser para la mentira, en lugar del ser para la muerte de los filósofos: un ser-máscara. ${ }^{36}$

Por su parte, Georges Didi-Huberman (2006) en su genealogía de la imagen refrenda, de alguna manera, las conjeturas sarduyanas. En su capítulo primero, revisa los inicios de la relación entre muerte e imagen, estrechándolos estrepitosamente, a partir de una relectura de los aportes de la Historia Natural de Plinio el Viejo (77 d.c), en el marco de un cuestionamiento arqueológico al trazado de la historia del arte. Allí, parece confirmar que la contradicción entre presencia-ausencia que rodea a la constitución de las imágenes, incluso, en su estatuto de arte, proviene de la experiencia de la muerte de otros. La imago -traducida por Didi-Huberman como imagen- fue originalmente necrológica: era una mascarilla de cera que se fabricaba

\footnotetext{
${ }^{34}$ Gabrieloni. "Literatura y artes". p. 128

${ }^{35}$ Lessing. Laocoonte o sobre los limites en la pintura y la poesía, p. 149-163

36 Sarduy. Obras Completas p. 1836.
} 
colocando un molde de yeso sobre el rostro de un muerto, que cumplía una función civil y jurídica al mismo tiempo, antes que una función estética. Luego, la misma sería expuesta en los atrios de las casas, junto imágenes de otros antepasados, acompañando con su potencia genealógica a los familiares, como ritual, cuando alguien moría. Para los romanos del siglo I, la imago era asumida como representación jurídica de la muerte, en tanto retrato de la ausencia de otro y estaba ligada -como propone María Guadalupe Silva- "a su condición de testimonio: la imagen era una copia de la identidad y tenía valor jurídico como impronta del antepasado". El objeto del retrato no era, en este sentido, artístico sino genealógico y consistía en certificar la identidad del ancestro, estaba allí para rendir homenaje a los mayores, establecer el linaje de la familia y sostener su memoria. Por lo tanto, la imago se constituía como "la máscara de la muerte", pero también como el signo de supervivencia: "un bien destinado a la posteridad". ${ }^{37}$ En este sentido, el planteo de Sarduy de un ser para la muerte, devenido en un ser-máscara que simula, pareciera corresponderse con las transformaciones que Didi-Huberman comienza a registrar en la época de Plinio: la pérdida de la denominada dignitas de la imago. El sentido primigenio del retrato fabricado bajo la voluntad de semejanza extrema comienza, ya en su origen, a desaparecer.

Como Sarduy sabe, máscara puede provenir del árabe maskarah que significa bufón o del latín mascus que significa fantasma, algo "al mismo tiempo estructurante y oculto, borrado para siempre, que sería como una definición". ${ }^{38}$

Por lo tanto, en el razonamiento sarduyano lo que se denomina "fondo" se vuelve más interesante que el "motivo", en la medida en que sobre ese fondo, ambos fenómenos, pintura y literatura, registran una doble inscripción. Por un lado, adquieren su famoso sentido de “decorado" y, por el otro, como la imago, representan "casi bancariamente", un capital:

En la Edad Media y en el Renacimiento no hay “anotaciones cromáticas". Un prado de Van Eyck puede ser botánicamente preciso en el sentido más milimétrico del término, las alas de un Ángel pueden llegar a una iridiscencia onírica, el mármol de un suelo puede armar con sus vetas una perspectiva falaz, pero en sus descripciones los escritores y pintores no utilizan el color. De un paisaje, por ejemplo, no sabemos nada, en cuanto a los elementos cromáticos, hasta muy tarde en la historia de Occidente. Grecia y Roma no fueron menos parcas $^{39}$.

\footnotetext{
${ }^{37}$ Silva. "El arte del recuerdo. Imágenes de José Lezama Lima”, p.173-175

${ }^{38}$ Sarduy. Obras Completas, p. 33

${ }^{39}$ Sarduy. Obras Completas, p. 1823
} 
Por otra parte, si profundizamos estas conceptualizaciones encontramos que, paradójicamente, cuando Severo pinta se afirma en la escritura: "Pinto algo que se parece a letras hebraicas. Según algunos, son letras de la Torá, son trazos minúsculos que se van acumulando hasta ser una especie de texto. Según otros, es como un tejido hindú, según otros, son como tejidos precolombinos, en fin, se parece mucho a una escritura". ${ }^{40}$

A la vez, cuando escribe, se reconoce envuelto en una práctica que emparenta con la pintura de Mark Rothko: "buscando plenamente el color, el rojo, la no-representación”. ${ }^{41}$ Por lo tanto, la noción de mimetismo que privilegia se escapa radicalmente de lo asumido como representación: "Al llegar a Europa no me bastaban las iglesias, los museos, los castillos y quesos de ese basto museo que es el continente, quería además y con ellos su doble en las palabras, su analogía en los sonidos, su otra verdad". ${ }^{42}$ En conclusión, la analogía plástica sarduyana se aloja en la memoria y mente del artista, construyéndose en la co-incidencia bipolar que funde la escritura y la imagen, entre la repetición de la letra y la metáfora del color. Las mismas, como en el hipérbaton elíptico del barroco, se vuelven procedimientos que reactivan, hasta armar un tejido denso, "una escritura que oculta otra escritura". ${ }^{43}$ Como define Severo, un doble fondo oculto que tendría en definitiva un carácter aurático o ritual. Siguiendo la tesis de Susan Buck-Morss en la que Benjamin concibe a la "experiencia" en términos neurológicos, es decir, en términos de un proceso que tiene lugar en la mente del artista, puesto que participa de la misma con la potencia orgánica de sus sentidos, la analogía plástica sarduyana nos permite reconsiderar, también, a la estética como un acontecimiento de percepción de lo sensible, donde se pone en juego lo humano y lo animal/natural. Al respecto, apunta Sarduy:

Los colores curan. Los colores y esa otra forma vibratoria de los colores que son las palabras. En el tantrismo se practica cromoterapia. La disposición de los diferentes rojos en el mandala, los círculos, la figura que ocupa el centro y las figuras anexas, en sus respectivos paraísos, tienen como función canalizar una energía, es decir, armonizar, el cuerpo y sus diferentes fluidos, sus distintas intensidades. En mí también la escritura es terapéutica. Escribo para curarme de algo. Del exilio en este caso (....) Quería ir hacia el continente, fuera de lo insular, hacia el espacio libre de América. Sentí esa pulsión (...) de tocar el continente. (...) esa trabazón simbólica del primer barroco, que se confunde entre nosotros con el naturalismo intrincado, con la escritura de lianas en la noche del continente, la horizontal del río inmenso, la cámara del eco vegetal. ${ }^{44}$

\footnotetext{
${ }^{40}$ Sarduy. Obras Completas, p. p.1832

${ }^{41}$ Sarduy. Obras Completas, p. 1836

${ }^{42}$ Sarduy. Obras Completas, p. 33

${ }^{43}$ Sarduy. Obras Completas, p. 1823

44 Sarduy. Obras Completas, p. 1823
} 
En octubre de 1990, año en que Severo se entera (a la vez que oculta) su VIH positivo, ${ }^{45}$ realiza una primera exposición individual de sus trabajos plásticos en la Galería Lina Davidov de París, bajo el título de Tableaux manuscrits. En ella, presenta una serie de cuadros tendientes a la pintura abstracta y a la abstracción geométrica, que tematizan el cruce entre imagen y escritura. Este es el caso de la serie de cuadros que realiza en acrílico sobre corteza de árbol pegada a lienzo, denominados "Escritura roja I, II y III" o del acrílico sobre papel de 16 x $13 \mathrm{~cm}$., que singulariza el título de la muestra. ${ }^{46}$ En dicho cuadro, "Tableau manuscrit"/ "cuadro manuscrito", Sarduy presenta una acumulación extraordinaria de pequeños grafos rojos, similares a letras, unidos por la repetición y la continuidad. Pequeñas manchas rojas son fundidas entre sí y montadas, por el fino pincel del artista, con la regularidad de una escritura sobre la tela. Como totalidad, componen una espacialidad, en cuya base se exponen distintas tonalidades de rojo. Al mismo tiempo, la trama cromática del lienzo presenta distintas zonas de luz y oscuridad, delimitadas mediante la incorporación respectiva de blanco y negro. Por lo tanto, es posible distinguir en el manuscrito pictórico de Sarduy dos instancias horizontales, cuyos cortes presentan, además, leves variaciones en el tamaño de los grafos.

La primera de estas partes se organiza a partir de la incorporación de un espacio "en blanco", que interrumpe la aparente linealidad de los caracteres propuestos. Sin embargo, dicha puesta en blanco no deja al descubierto un vacío, sino que, por el contrario, permite visibilizar entre las capas de grafos rojos, una línea de trazos preexistentes de un color más débil, casi anaranjado. Vistos a la distancia, estos grafos materializan en la generalidad del cuadro una imagen que expone una discontinuidad puesto que, como un palimpsesto, conserva en la superficie las huellas de ciertos trazos anteriores. Este fondillo naranja de "Tableau manuscrit" muestra, en el marco analógico de una imitación plástica de la escritura, la instancia de un vacío aparente que vehiculiza un trabajo hecho capa sobre capa. Por lo tanto, como quien tabula una línea entre párrafos para mostrar su veladura, Severo presenta, nuevamente, su modo de concebir al mimetismo:

\footnotetext{
45 En Apuntes de una biografía familiar su hermana da cuenta de esto. http://www.severo-sarduyfoundation.com/vida.htm

${ }^{46}$ Nos referimos a Tableau Manuscrit. Estos y otros cuadros de Severo Sarduy se exhiben conforme a los derechos de reproducción que los rigen, en el portal web: “Ciudad de la pintura. Pinacoteca virtual”, cuya consulta puede hacerse en la siguiente dirección: http://pintura.aut.org/. Fecha de la última visita realizada: diciembre de 2012. Debido a precisas restricciones no podemos reproducirlos aquí.
} 
A partir de la nada y en función de ella, más presentes cuanto más intensas son las imitaciones, más logrados los camuflajes, más exactas las analogías y usurpaciones del modelo, deben leerse los fenómenos que enumero, los cuales a su vez, no son más que la teatralidad y la saturación máxima, vistos desde la vacuidad inicial, de todos los otros. ${ }^{47}$

A la vez, en "Tableau manuscrit" se observa con predominancia la paleta cromática privilegiada por el cubano. La misma está constituida por el uso del rojo, el blanco y el negro. $\mathrm{Al}$ respecto, corresponde destacar que estos tres colores han sido interpretados en una línea de continuidad con los planteos iniciados por Georges Bataille en su Historia del Ojo (1928). Allí, el rojo, el blanco y el negro aluden respectivamente a la sangre, al esperma y a la explosión originaria que explica, frente al vacío, la existencia de un firmamento "totalmente oscuro". ${ }^{4}$

En un texto reciente que se ocupa de los vínculos interartísticos presentes en la obra sarduyana, Rolando Pérez (2012) propone que estos colores, tanto en el mencionado texto de Bataille, como en el poemario Big Bang (1979) de Severo Sarduy, son invocados en el marco de una "eroto-estética" que pone en relación distintos órdenes de interrogación sobre "lo micro" y "lo macro", en la medida en que son elementos utilizados para trazar una relación entre el cuerpo y el universo. ${ }^{49}$ No obstante, nuestra lectura privilegia una comprensión de estas relaciones como tópicos participantes de la exploración sarduyana del mimetismo, inscriptas, por él mismo, bajo el marco de la dualidad naturaleza/cultura apuntada por Roger Caillois (1937). De igual modo, siguiendo a Pérez (2012) podemos considerar que: “el blanco, el color del esperma, es también el color de la eyaculación interestelar que llamamos Vía Láctea, y es mejor apreciado contra el negro (fondo) del firmamento, en el cual el siguiente color prominente es el rojo". ${ }^{0}$

Por otra parte, el segundo fragmento de "Tableau manuscrit", se recorta a partir de la inscripción de dos líneas de grafos negros, que vuelve visible otro de los intereses filosóficos de Sarduy: la integración de los órdenes dinámicos del cosmos, en la pintura y escritura china. Resulta evidente que un análisis de los tópicos del orientalismo presentes en la obra de Sarduy excede el propósito de este trabajo. No obstante, en el marco de estas consideraciones sobre el color, corresponde tener en cuenta sus planteos en torno al vacío, asumido como potencialidad generadora de un cruce particular entre imagen y escritura:

\footnotetext{
${ }^{47}$ Sarduy. Obras Completas, p. 1272

${ }^{48}$ Bataille. Historia del Ojo, p. 9. Por otra parte, el color negro pone en relación la explosión de la eyaculación y con la explosión originaria del universo representada por la teoría del Big bang.

${ }^{49}$ Pérez. Severo Sarduy and the neo-baroque image of thought in the visual arts, p. 119. La traducción es nuestra.

50 Pérez. Severo Sarduy and the neo-baroque image of thought in the visual arts, p. 118.
} 
En la óptica china, el Vacío no es, como pudiera suponerse, algo vago o inexistente, sino un elemento eminentemente dinámico y operante. Relacionado con la idea de los soplos vitales y con el principio de alternancia entre el Ying y el Yang, el Vacío constituye el lugar por excelencia donde se operan las transformaciones, donde lo Lleno podría alcanzar su verdadera plenitud. Es el Vacío el que, introduciendo en un sistema dado la discontinuidad y la reversibilidad, permite a las unidades constitutivas de ese sistema, sobrepasar la oposición rígida y el desarrollo en sentido único, y permite al mismo tiempo al hombre la posibilidad de un acercamiento totalizante del universo. $^{51}$

Finalmente, luego de la primera exposición personal consignada, Severo Sarduy realiza una segunda y última, llevada a cabo, también, en la Galería Lina Davidov, en febrero de 1993. Sin embargo, el interés de Sarduy por la imagen no es exclusivo de sus últimos años. Puede leerse, también, en el primer poema que publicara en Camagüey, su ciudad natal, a los 16 años:

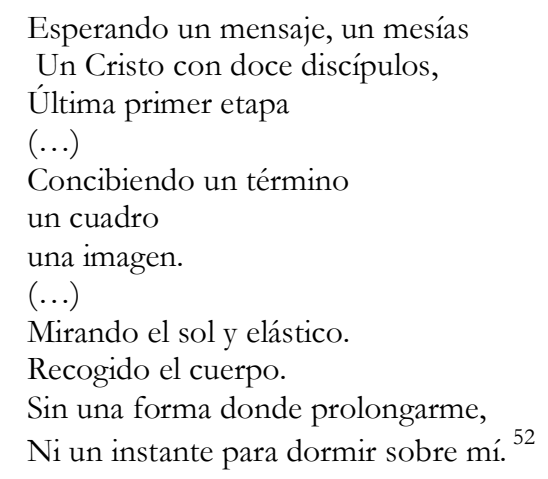

Por lo tanto, fechar el inicio del trabajo plástico del cubano a partir de su llegada a Francia resulta, cuanto menos, apresurado. Su interés por la pintura se verifica en una cantidad importante de entrevistas y comentarios publicados en diversos medios participantes de la explosión que caracterizó a la prensa literaria cubana a partir de la Revolución. ${ }^{53}$ Incluso, en febrero de 1959 funda, junto a su amigo Frank Rivera (colega en el grupo Arquipiélago con el que dio sus primeros pasos poéticos) una página de salida fluctuante en el periódico Mañana Libre llamada: "Arte Literatura". ${ }^{4}$

\footnotetext{
51 Sarduy. Obras Completas p. 1272

52 Poema "Tres" de 1953. Recogido por Romero. Severo Sarduy en Cuba 1953-1961, p.19-20

${ }^{53}$ Cira Romero(2007) compila una importante cantidad de trabajos de Severo Sarduy sobre pintura publicado por ejemplo, en suplemento cultural Lunes de Revolución, en Nueva Revista Cubana, en Mañana libre y en Combate 13 de Marzo

${ }^{54}$ Es curioso cómo manifiestan las variables de esta relación, puesto que en las entrevistas a pintores que él mismo realiza para éste suplemento, a veces se refiere a la página como "Arte y Literatura", otras con guión "Arte-Literatura" y a veces sin nada, como optamos por referirla, asumiendo el riesgo de que se deba a errores a tipográficos o de reproducción.
} 
En consecuencia, la magnitud que los rastros plásticos adquieren en el archivo sarduyano nos pone en una situación de dilación frente a los mismos. Aún no los hemos recogido del todo y tampoco podemos asegurar adónde comienzan. Debido a ello, probablemente sólo baste leer, como propone Antelo, "para que el origen advenga" asumiendo a la imagen -como propone Didi-Huberman- "como un elemento del futuro, de la duración". ${ }^{55}$ Puesto que si algo hemos aprendido es que, aún cuando la imago no nos pertenezca, estamos fatalmente obligados ante ella -como lo hace Severo- a tomar una posición.

\section{Referencias bibliográficas}

Antelo, Raúl. Crítica Acéfala. Bs. As: Ed. Grumo, 2008. $28,2009,11-20$. "Postautonomía: pasajes", Pasajes. Revista de pensamiento contemporâneo, nro. "El realismo y su sombra", in: Caballero Vázquez, Miguel; Rodríguez Carranza, Luz; Soto van der Plas, Christina, (edit). Imágenes y Realismos en América Latina.

Simposio Internacional. Leiden., 2011. Actas on-line Disponible en: http://imagenesyrealismosleiden.wordpress.com

Barthes, Roland. Sade, Fourier, Loyola. Rio de Janeiro: Martins Fortes, 1979.

Bataille, Georges. Historia del Ojo. [Trad. Margo Glantz] México D.F: Ediciones Coyoacán, 1994.

La noción de gasto, 1933. Disponible en: www.philosophia.cl

Buck-Morss, Susan. "Estética y anestésica. Una reconsideración del ensayo sobre la obra de arte", Walter Benjamin, escritor revolucionario. Bs. As.: Interzona, 2005.

Cherri, C. Leonel. "Políticas de muerte y políticas de sentimiento en un corpus latinoamericano" en VIII Congreso Internacional de Teoría y Crítica Literaria Orbis Tertius. «Literaturas compartidas». La Plata, FaHCE, mayo de 2012. (en prensa).

Didi- Huberman, Georges. Ante el tiempo. Historia del arte y anacronismo de las imágenes. Buenos Aires: Adriana Hidalgo editora, 2006.

Derrida, Jacques. La différance. Márgenes de la filosofía. (Trad. Carmen González Marín: Modificada: Horacio Potel), Madrid: Cátedra, 1998

www.derridaencastellano.com La verdad en pintura, 1978. (Modificada: Horacio Potel). Disponible en:

Gabrieloni, Ana Lía. "Literatura y artes", in: Miguel Dalmaroni (dir.) La investigación literaria. Problemas iniciales de una práctica. Santa Fe: Ediciones UNL, 2009.

Jay, Martin. "La reconstitución posestructuralista de la experiencia". Cantos de Experiencia. Variaciones modernas sobre un tema universal. Buenos Aires: Paidós, 2009.

Kracauer, Sigfried. Historia. Las últimas cosas antes de las últimas (Trad. Miguel Vedda). Buenos Aires: Las Cuarenta, 2010

Lacan, Jacques. Seminario 19: ...O peor. 1971-1972. (Texto establecido por Miller). 1era. Edición Español. Buenos Aires: Paidós, 2012.

\footnotetext{
55 Didi-Huberman. Ante el tiempo, p.12
} 
Laddaga, Reynaldo. Espectáculos de realidad. Ensayos sobre la narrativa latinoamericana de las últimas dos décadas. Rosario: Beatriz Viterbo Editora, 2007

León, Francisco. "La vacuidad de todo: la pintura de Severo Sarduy", Revista Digital Ojos de papel. Barcelona, 2001. Disponible en: http:/ / www.ojosdepapel.com/index.aspx?article $=908$

Lessing, Gotthold E. Laocoonte o sobre los limites en la pintura y la poesía. Trad. Enrique Palau, Madrid: Orbis, 1985.

Link, Daniel. "Critica Acéfala". Reseña. Boletim de Pesquisa - NELIC, V. 8, No 12 / 13, 2008.

Ludmer, Josefina. "Notas para Literaturas Posautónomas III". 31/7/2010. Disponible en: http://josefinaludmer.wordpress.com/2010/07/31/notas-para-literaturas-posautonomasiii/

Perez, Rolando. Severo Sarduy and the neo-baroque image of thought in the visual arts. West Lafayette, Indiana: Ed. Purdue University, 2012. 2007.

Romero, Cira. Severo Sarduy en Cuba 1953-1961. Santiago de Cuba: Editorial Oriente,

Santucci, Silvana. "Sarduy y el Neobarroco. Interpretaciones sobre lo político en el arte". Recial. Revista del Centro de Investigaciones de la Facultad de Filosofía y Humanidades Área Letras -UNC, nro. 2, 2011, p. 1-14.

"Otro ángelus novus. Imágenes de la historia de Severo Sarduy", en

VIII Congreso Internacional de Teoría y Crítica Literaria Orbis Tertius. «Literaturas compartidas». La Plata, FaHCE. Mayo de 2012. (en prensa).

Sarduy, Severo. Obras Completas Tomo I. México: FCE, 1999

Obras Completas Tomo II. México: FCE, 1999

Silva, María Guadalupe. "El arte del recuerdo. Imágenes de José Lezama Lima.", in: Graciela Salto (coomp.) Ínsulas y poéticas. Figuras literarias en el caribe. Buenos Aires: Biblos, 2012 